\title{
La imagen del caballero en la novela artúrica
}

\author{
Rosalba LENDO FUENTES \\ Universidad Nacional Autónoma de México
}

Una de las características principales de la novela medieval francesa en sus inicios, a mediados del siglo XII, fue haber concedido un lugar privilegiado al amor. Bajo la influencia de la poesía lírica, el género alcanzó su pleno desarrollo en la novela artúrica, definiéndose como una ficción de aventuras y amor. Ya desde los "romans antiques" se perfila un nuevo tipo de héroe, diferente del guerrero de los cantares de gesta; se trata de un héroe valiente y cortés, el caballero, quien para aspirar a tan alto rango tiene que destacar tanto en el plano de la proeza como en el amoroso. Sin embargo, no es sino con Chrétien de Troyes cuando asistimos al verdadero nacimiento de este héroe en el que se conjugarán los valores de un nuevo ideal de sociedad, la cortesía, reflejo de las más altas aspiraciones de la nobleza, a la que está dirigida la novela.

La leyenda del rey Arturo, originaria de Inglaterra, cristalizó a partir de entonces en la creación novelesca. Chrétien de Troyes la adaptó al ideal caballeresco y cortés de la época. Su obra tuvo una influencia determinante en los escritores de los ciclos artúricos del siglo XIII, pues en ella quedaron establecidas las bases que permitirian la evolución del género: un tiempo y un espacio en el que se desarrolla la ficción, la Gran Bretaña legendaria del rey Arturo, una serie de personajes con características precisas y un modelo de estructura narrativa basado en la "aventura", concepto que define aquellos acontecimientos inesperados que sorprenden al caballero y que rompen el equilibrio del espacio artúrico. La noción de "aventura" permitió la creación del tipo del caballero andante, protagonista de la novela. Se trata de un caballero solitario en busca de hazañas y aventuras que le den renombre y lo hagan digno del amor de su dama, pues es finalmente por ella por quien realiza todo tipo proezas.

Con la redacción de los grandes ciclos durante el siglo XIII, el género sufrió transformaciones importantes que se vieron reflejadas en la imagen del caballero. Los cambios se debieron en gran parte a la introduc- 
ción del tema del Grial en las novelas cíclicas. Chrétien de Troyes, en el Conte du Graal, había sido el primero en mencionar este objeto misterioso, retomado después en la trilogía de Robert de Boron (principios del siglo XIII), quien lo identifica con el cáliz de la Última Cena y en el que José de Arimatea recogió la sangre de Cristo. A partir de este momento, la búsqueda de la Santa Reliquia será la más alta aventura, destinada a uno de los caballeros de la Mesa Redonda. Pero aquí ya no se trata de una aventura mundana sino espiritual; y por ello, el elegido para llevarla a cabo ya no puede ser un caballero valiente y cortés, sino casto y puro. Así, desde el Conte du Graal se perfila la nueva orientación de la novela artúrica y la nueva imagen del caballero: el aspecto religioso se vuelve esencial en la ética caballeresca.

El segundo ciclo, el Lancelot-Graal o ciclo de la Vulgata (1215-1230), fue concebido bajo una triple perspectiva: caballeresca, cortés y religiosa. Aquí se narra de principio a fin la trayectoria de la caballería artúrica y podemos observar claramente las transformaciones que fue sufriendo, de acuerdo a los nuevos valores que se plantearon y que permitieron la creación de un héroe ideal. El objetivo del presente estudio es definir los rasgos esenciales y las modificaciones más significativas de la imagen del caballero en la novela artúrica francesa.

La novela artúrica nace en una época de grandes cambios en la sociedad medieval. La reafirmación del poder monárquico, los lazos que se empiezan a establecer entre el rey y una burguesía en plena expansión, en detrimento de la nobleza que va perdiendo poco a poco sus privilegios y poder dentro de la estructura político-social, son algunos de los factores que marcarán estas transformaciones. En cierta medida marginada, la clase feudal y, dentro de ella, la caballería, orden guerrera instituida por Dios, ${ }^{1}$ según la ideología medieval, y encargada de garantizar la paz en la sociedad, trató de luchar por conservar su poder. A la idea de una misión divina, se sumaron el espíritu aristocrático, la conciencia de linaje, el sentido del honor y la fidelidad a su señor, valores en los que se fundamentó la cohesión de esta clase y que hicieron del caballero la más alta figura en el seno de la sociedad feudal.

Manifestación literaria de una época en la que el poder feudal en crisis toma conciencia de sus intereses y de la necesidad de justificarlos, la novela artúrica, a través de un universo imaginario y con una visión aris-

${ }^{1}$ Li plus haut ordre que Dex ot faite et comandee [la más alta orden que Dios haya hecho e instaurado], precisa Chrétien de Troyes en el Conte du Graal (Méla, 1994: 990). 
tocrática de éste, se encargará de exaltar la moral y los valores de su clase con el afán de afirmar su superioridad frente a los otros grupos sociales. Galván, Iván, Lanzarote, y los demás caballeros de la Mesa Redonda se convierten en el prototipo ejemplar de la clase feudal. La gloria que alcanzan gracias a sus grandes hazañas es inseparable de su condición de caballeros. Así, la nobleza vio en este nuevo género una manera, por lo menos simbólica, de afirmar su dignidad de clase. Su reacción no fue más allá de lo artificial, pues, como lo señala Jean Frappier: "L'irrealité même des exploits accomplis par les chevaliers errants nous laisse entrevoir une noblesse qui a renoncé en partie à son activité pour se réfugier dans la contemplation de hauts faits imaginaires" (Frappier, 1977: 23). ${ }^{2}$

La novela artúrica propuso a esta sociedad de las cortes francesas un modelo de identificación. Haciendo una especie de síntesis entre el mito y la realidad de la época, los autores elaboraron una imagen del caballero, tal como la querían ver los grandes señores feudales. De la épica se retomó el modelo del guerrero, en el que se conjugaron no sólo el valor, la proeza y la fuerza física, sino también un alto sentido del honor y de la fidelidad, características que seguirán siendo un valor esencial en el caballero. Pero las exigencias corteses hicieron necesarias modificaciones importantes. La proeza guerrera, cualidad dominante del héroe épico, pero presentada algunas veces como violencia brutal, tuvo que ser canalizada. En este sentido, el amor jugó un papel determinante, y se logró establecer un perfecto equilibrio entre armas y amor. A esto se sumó una serie de valores distintivos de la cortesía: la nobleza de alma, la mesura, la generosidad y la apertura de espíritu son algunos de ellos.

La belleza y la juventud son igualmente cualidades distintivas del caballero. En efecto, los destinados a tan alta misión tenían que ser fuertes y valientes, pero también apuestos, ${ }^{3}$ ya que, en el universo cortés, la fealdad era signo de vileza. Así, la belleza inigualable de Lanzarote está intimamente ligada a su perfección moral. La belleza viene en general acompañada de juventud. Pero no es suficiente ser joven de edad, hay que serlo también de espíritu y de disponibilidad para poder emprender cualquier tipo de aventura.

El honor es sin duda alguna un valor esencial de la moral caballeresca. El caballero debe temerle más a la deshonra que a la muerte; debe poseer

${ }^{2}$ La irrealidad de las hazañas llevadas a cabo por los caballeros andantes permite vislumbrar una nobleza que ha renunciado en parte a su actividad para refugiarse en la contemplación de grandes hazañas imaginarias.

${ }^{3}$ Ver n. 5, pasaje que cito del Lancelot en prose. 
una actitud y un valor inquebrantables, y no retroceder ante nada, pues es su honor el que está en juego. ${ }^{4}$ Es este alto sentido del honor lo que finalmente lo llevará a alcanzar la gloria. Toda acción contraria no sólo al honor, sino a la justicia, a la mesura y a la lealtad, son faltas graves que repercutirán en la imagen del caballero, afectando a todo su linaje, así como la reputación de la comunidad a la que pertenece. Como lo apunta Jean Flori:

La noción de honor ocupa una posición central en la ideología caballeresca... Es menester vincular este aspecto a la noción de linaje, elemento esencial de la ideología aristocrática, de la idea de nobleza. El honor no es sólo una virtud personal, es un valor de clan, un bien colectivo que cada generación que lo hereda debe procurar conservar. Por eso la vergüenza y la deshonra (unida sobre todo a la cobardía y a la traición, pero también a cualquier otra agresión al código moral admitido) no recae sólo sobre su autor, sino que se transmite como una tara genética a todo el linaje. Ahora bien, apenas es posible "conservar" este honor como se haría con un bien material, guardándolo y atesorándolo; es menester incrementarlo [...] mediante la acción gloriosa (Flori, 2001: 261).

Son pues las grandes hazañas las que van a incrementar este herencia de un gran linaje, este valor que es el honor, entendido como prestigio, renombre o consideración pública.

$\mathrm{Si}$ es verdad que algunos de los valores que caracterizan al caballero se transmiten dentro de un linaje noble, también es cierto que otros se aprenden desde la infancia. Uno de los temas recurrentes de la novela cíclica es precisamente el de la infancia del héroe, que permitió a los autores inventar un origen a sus personajes principales, con el fin de ofrecer su historia completa, desde su nacimiento hasta su muerte. Ya desde el Conte du Graal, donde Chrétien de Troyes relata la adolescencia de Perceval, se observa esta inquietud que cristalizará plenamente en los grandes ciclos. La época de la infancia del héroe es pues la de su formación caballeresca. Al principio del Lancelot en prose, el relato de la infancia de Lanzarote ofrece un ejemplo claro y detallado de la educación del caballero.

El aprendizaje del héroe comprende tres aspectos: la iniciación caballeresca, la cortés y la religiosa. Sin embargo, mientras que Perceval, en el Conte du Graal, se ve obligado a descubrir y asimilar por sí mismo la

${ }^{4}$ Ver n. 5. 
práctica de la caballería y lo esencial de los valores y comportamientos corteses y religiosos, Lanzarote será educado por la Dama del Lago en un mundo maravilloso situado en las profundidades de un lago. Desde muy pequeño es confiado a un tutor, quien se encarga de enseñarle todo lo relacionado con la práctica de las armas y el arte de la caza. La Dama del Lago se ocupa de la educación moral, en la que el niño, y luego el adolescente, aprenderá los derechos y deberes del caballero, su misión dentro de la comunidad. Recordemos parte del famoso pasaje en el que la dama explica a Lanzarote lo que es la caballería y enumera las cualidades que definen al caballero:

Ce furent li grant et li fort et li bel et li legier et li leial et li preu et li hardi, cil qui des bontez del cuer et del cors estoient plain. Au commencement [...] fu devisé a celui qui voloit estre chevaliers [...] qu'il fust cortois sans vilenies, deboenneires sanz felenie, piteus vers les soffraiteus, et larges et appareilliez de secorre les besoigneus, prelz et appareilliez de confondre les robeors et les ocianz, droiz jugierres $[\ldots]$ Chevaliers ne doit por paor de mort nule chose faire o l'an puise honte conoistre ne aparcevoir, ainz doit plus doter honteuse chose que mort sossfrir (Mosès 1991: 400). ${ }^{5}$

Aquí se resume la misión fundamental de la caballería: hacer que la justicia y el orden sean respetados en un mundo que es con frecuencia amenazado por las fuerzas del mal. Todas las cualidades del caballero sirven a este fin, a esta gran tarea a la que están dedicados los caballeros de la Mesa Redonda.

Pero Lanzarote aprenderá también, gracias a la educación de la Dama del Lago, las exigencias del amor cortés, que luego pondrá en práctica para conquistar a Ginebra. A los aspectos que hemos mencionado se suma, en el caso de Tristán, cuya infancia es relatada al principio del Tristan en prose, una educación artística e intelectual que convertirá al héroe ro sólo en un caballero ejemplar, sino también en un hombre cultivado, poeta y músico.

${ }^{5}$ Eran grandes, fuertes, hermosos, ágiles, pero también leales, nobles y valientes; es decir tenían cualidades y virtudes tanto del cuerpo como del corazón [...] se le exigía al que deseaba ser caballero [...] que fuera cortés sin villanía, agradable sin doblez, misericordioso con los que sufrían, generoso y bien dispuesto a socorrer a los necesitados, rápido y preparado para castigar a los ladrones y asesinos, juez recto [...] Por miedo a morir, el caballero no debe hacer nada de lo que se pueda derivar o suponer alguna afrenta, antes bien, más debe temer la deshonra que la muerte (Alvar, 1988: 165). 
Como ya lo señalamos, el tipo del caballero andante y su misión en el mundo fueron definidos con precisión en la obra de Chrétien de Troyes. Así, desde la primera mención que este autor hace del chevalier errant qui aventure allast querant (Le Chevalier au Lion, ed., Hult, 1994: vv. 259-260) [caballero andante que va buscando aventura] queda muy clara la característica esencial de este nuevo héroe. El termino aventure ("aventura") denota, como lo señala Marie-Luce Chênerie (1986: 76), cierta imprecisión en la que se pone de manifiesto que el mismo héroe no sabe bien a dónde lo llevará su búsqueda que, aunque inicia con un objetivo preciso, lo conduce a una serie de acontecimientos cuyo desenlace desconoce. Una vez que el caballero sale de la corte en busca de la aventura, el desarrollo de la narración está subordinado a su desplazamiento en un espacio donde la manifestación de lo maravilloso es constante. Su tarea consiste en luchar contra todo tipo de seres y contra toda forma de violencia, injusticia y' desorden que impiden la armonía y la paz. El éxito en todas las pruebas que va enfrentando es lo que le dará un lugar en la sociedad caballeresca. La aventura es pues la razón de ser y de existir del caballero andante; está hecha para este héroe, cuyo valor, característica fundamental, lo incita precisamente a buscar el peligro para mostrar su arrojo. De aventura en aventura descubrirá su verdadera identidad, su lugar en el mundo y el objeto de sus más altos deseos.

El caballero andante es un héroe solitario y sus aventuras tienen un carácter individual. La búsqueda, como lo apunta Carlos García Gual, es una senda de perfeccionamiento de un personaje elegido (1994: 99). Sin embargo, si es verdad que las acciones, por ejemplo las de un caballero como Lanzarote, son individuales y supeditadas no al rey sino a Ginebra, también es cierto que repercuten de manera decisiva en la gloria de la comunidad. El poder de Arturo y de su reino se debe pues a las grandes hazañas de estos caballeros andantes, miembros de la Mesa Redonda, conscientes de su responsabilidad con el rey y de su misión dentro de la comunidad. El caballero es de alguna manera el garante de los intereses de esta comunidad y es siempre el rey el que lo designa para determinada misión; es en este héroe en quien reposa el orden del universo artúrico. La relación planteada entre Arturo y sus caballeros es, en el plano de la ficción, la imagen de una relación ideal entre el rey y sus grandes vasallos, representada a través de la Mesa Redonda, símbolo del poder y la gloria del reino artúrico.

Si la función de los caballeros de la Mesa Redonda es garantizar la supremacía del reino, la del rey es asegurar la permanencia y la unidad de esta elite de guerreros, cuya fuerza reside precisamente en su cohesión, 
en su espíritu de compañerismo y fidelidad, entre ellos mismos, pero también, y sobre todo, hacia su señor. Arturo es el garante de los valores corteses y caballerescos de esta sociedad. El poder del reino reposa en esta relación armónica que el rey establece con sus caballeros. Se trata, como Dominique Boutet lo señala, de una repartición ideal de funciones: "Au roi la fonction de justice et l'obligation de largesse, aux vassaux la fidélité et la tâche de maintenir, voire d'étendre l'ordre arthurien, la paix arthurienne dont le roi n'est que le garant moral" (Boutet, 1979: 94). ${ }^{6}$

Ésta es la imagen que ofrece la novela artúrica, la de un rey ideal cuya función principal es velar por la justicia y la paz, en una admirable corte a la que viene todo aquel que necesita ayuda, como el escudero que, en la Suite du Merlin (novela perteneciente al ciclo Post-Vulgate escrito hacia 1240), llega con su señor herido de muerte:

Rois Artus, a toi me fait venir li grans besoins que jou ai de t'aide et de ton secours, et se te dirai pour coi. Voirs est que tu ies rois et sires de ceste terre par la grasce de Nostre Signour, et quant tu fus saisis dou roiaume tu creantas devant le peuple que tu amenderoies a ton pooir tous les mesfaits que on feroit en ta terre, fust chevaliers ou autres. Et il est ore ensi avenu c'uns chevaliers, ne sai qui il est, a par son orgueil mon signeur orendroit ochis (Roussineau, 1996: $\S 37,11,6-14)^{7}$

Pero a su corte llegan también los mejores caballeros, de todas las nacionalidades, atraídos por el gran renombre de Arturo, cuya segunda cualidad es, como ya lo mencionamos, la "largesse". En efecto, el rey recibe y recompensa generosamente a estos caballeros, especialmente a los miembros de la Mesa Redonda, que constituye de alguna manera el centro de este maravilloso universo cortés. La rima que se observa desde Chrétien de Troyes: table reonde - monde, traduce muy bien esta idea.

Sin embargo, la Mesa Redonda se vuelve también, a partir del ciclo de Robert de Boron, una institución creada bajo la orden de Dios y destinada a una alta misión: la búsqueda del Santo Grial. Así, al prestigio y

${ }^{6} \mathrm{Al}$ rey la función de justicia y la obligación de generosidad, a los vasallos la fidelidad y el deber de mantener, incluso extender, el orden artúrico, la paz artúrica, de lo que el rey es únicamente garante moral.

${ }^{7}$ Rey Arturo, vengo ante ti por la gran necesidad que tengo de tu ayuda y socorro. Y te diré por qué. Eres rey de esta tierra por gracia de Nuestro Señor, y cuando tomaste posesión del reino juraste al pueblo hacer lo que estuviera en tus manos para reparar todas las faltas cometidas por caballeros o por cualquier otra persona. Y sucedió que un caballero orgulloso, que no sé quién es, mató a mi señor. 
poder que caracterizan a esta institución dominada por el espíritu de familia, la lealtad feudal, la bravura y la proeza de sus miembros, se suma también su carácter sagrado. La fundación de la Mesa Redonda, creada a imagen de la mesa de la Ultima Cena y de la del Santo Grial, se convierte en un acto religioso, sin que por ello se elimine su aspecto profano. La Mesa Redonda es la expresión del ideal caballeresco, en el que se conjugaron los más elevados valores profanos y religiosos.

Una de las características fundamentales del segundo y más importante ciclo artúrico, el Lancelot-Graal (1215 y 1230) es precisamente la presencia de estos dos aspectos, el profano, es decir el cortés, y el religioso, que marcó una importante transformación en la imagen del caballero. En este vasto conjunto anónimo, formado por la Histoire du Saint Graal, el Merlin y su continuación, el Lancelot en prose, la Quête du Saint Graal y la Mort du roi Arthur, se planteó la integración de los principales elementos de la tradición artúrica.

Así, en el Lancelot en prose se retoma de Chrétien de Troyes el tema del amor adúltero entre Lanzarote y Ginebra, que será ampliamente desarrollado. El culto al amor, bajo la forma sublimada de la fin'amor, es decir del sentimiento llevado a la perfección, es una de las manifestaciones de la ideología caballeresca mejor logradas por los autores de novela artúrica, y Lanzarote es su máximo representante. A través de este personaje, el fin'amant por excelencia, se da la alianza ideal entre proeza y amor, que caracteriza a la figura literaria del caballero. Ya desde Chrétien de Troyes y las primeras versiones del Tristan en prose, los motivos clave que definen al amor cortés en la poesía lírica (el amor adúltero, el deseo amoroso, el servicio de amor, la sumisión del amante vasallo, la espera de una recompensa, la dicha y el dolor de amar) habían sido adaptados a la novela. Todos estos motivos los encontramos en la relación de Lanzarote y Ginebra. El amor es, en este héroe, principio de virtud caballeresca, y las proezas que va acumulando en nombre de su dama le permitirán alcanzar una posición preponderante dentro de la comunidad y ser así digno del amor de una reina. Este es el consejo que la Dama del Lago da a Lanzarote, en el Lancelot en prose, cuando se va a la corte de Arturo para ser armado caballero: "que vous ne metoiz ja vostre cuer en amor qui vos face aparecir mais amander, car cuers qui por amor devient pareceus ne puet a haute chose ataindre, car il n'osse. Mais cil qui tozjorz bee a amender puet ataindre a hautes choses, autresin com il les ose anprandre" (Mosès, 1991: 556). ${ }^{8}$

${ }^{8}$ No pongáis vuestro corazón en un amor que os haga ser peor, sino en uno que os 
Si en un principio el Lancelot en prose es una clara exaltación del amor cortés, encarnado en la figura de Lanzarote, a medida que se va introduciendo el tema del Grial y se prepara la siguiente parte del ciclo, la Quête du Saint Graal, la novela adquiere un tono cada vez más religioso. Se empiezan a condenar los valores corteses que, en la Quête du Saint Graal, serán la causa del fracaso de Lanzarote en la búsqueda del Grial. Sin embargo, cuando el héroe se entera, al final del Lancelot en prose, de que no es digno de alcanzar la gloria del Grial por el pecado cometido con Ginebra, no lo lamenta en absoluto, pues, como él mismo le dice a la reina, es este amor lo que lo hizo el mejor caballero del mundo. Para Lanzarote el amor es absoluto o no es amor, y esta locura es lo más digno que puede existir, pues gracias a ella se llega a la razón y al honor.

Pero el autor de la Quête du Saint Graal ve las cosas de manera distinta; el amor cortés se convierte aquí en pecado de lujuria y la proeza motivada por este sentimiento es vista como la búsqueda de una gloria vana. A imagen de los Templarios, de estos soldados de Cristo en los que Bernard de Clarivaux (en De laude Novae Militiae ad Milis Templi) celebró el nacimiento de una caballería ejemplar, síntesis del ideal caballeresco y guerrero y del monástico, el nuevo héroe de la novela debía consagrar sus acciones al servicio de Dios. La estricta observancia de la fe cristiana, la castidad, la humildad, la penitencia y la renuncia a toda gloria mundana son los nuevos valores de la caballería celestial, como la llama el autor de la Quête, encarnada en la figura de Galaad, el elegido para llevar a buen fin la búsqueda del Grial, es decir la búsqueda de Dios. Tal como lo dice el ermitaño al inicio de esta novela, se trata de la suprema aventura, que ya no tiene nada de mundano, como las aventuras a las que estaban acostumbrados los caballeros:

Ceste Queste n'est mie queste de terriennes choses, ainz doit estre li encerchemenz des grans secrez et des privetez Nostre Seignor et des grans repostailles que li Hauz Mestres mostrera apertement au boneuré chevalier qu'il a esleu a son serjant entre les autres chevaliers terriens, a qui il mostrera les granz merveilles dou Saint Graal, et fera veoir ce que cuers mortex ne porroit penser ne langue d'ome terrien deviser (Pauphilet, 1984: 19). ${ }^{9}$

haga mejorar, pues el corazón que por amor se hace perezoso no puede alcanzar altas cosas, pues no se atreve; pero el que todos los días se esfuerza en mejorar, alcanzará grandes cosas ya que se atreve a emprenderlas (Alvar, 1988: 233).

${ }^{9}$ Esta Demanda no es búsqueda de cosas terrenales, sino que debe ser persecución de los grandes secretos y misterios de Nuestro Señor y de los arcanos que el Gran Maes- 
Ya desde el Conte du Graal de Chrétien de Troyes se observa esta búsqueda de valores más elevados que trasciendan totalmente lo terrenal de la cortesía. En esta novela, la historia de amor de Perceval y Blancaflor es sólo una etapa en el camino de perfección del héroe, cuya verdadera meta es espiritual: el Grial, la sainte chose que vio en el castillo del Rey Pescador. Perceval es esperado allí como un gran libertador que devolverá la salud al rey y al reino entero, así como lo hace Galaad, el nuevo héroe que sustituye a Perceval en la Quête du Saint Graal. Pero Galaad llega todavía más lejos, pues logra tomar posesión de la Santa Reliquia y acceder así a la mística contemplación. Fue en este héroe donde se reflejaron las más altas pretensiones, simbólicas por supuesto, de una clase feudal en crisis: penetrar, mediante la perfección caballeresca, en la esfera de lo sagrado.

Si bien es cierto que ni el ideal místico de la Quête du Saint Graal ni el cortés del Lancelot én prose sobreviven en la Mort du roi Arthur, última parte del ciclo Lancelot-Graal, donde el fin de la búsqueda del Grial marca el fin del reino artúrico, y el descubrimiento del adulterio entre Lanzarote y Ginebra provoca la crisis que lleva a los caballeros de la Mesa Redonda a su destrucción; también es verdad que la imagen del caballero forjada por los autores franceses de novela artúrica sí perduró después de la Edad Media y trascendió el marco puramente feudal. En efecto, las cualidades de este héroe: la valentía, la cortesía, la generosidad, el servicio a los demás, la lealtad y el espíritu de aventura, entre muchas otras, dejaron una huella imborrable. Y fueron muchos los escritores y lectores que, en los siglos posteriores, rindieron homenaje a estos grandes héroes, recordándolos algunas veces con cierta ironía, como Cervantes, y otras con un respeto absoluto como Jean Chapelain, quien en su diálogo De la lecture des vieux romans (1647), al hablar del Lancelot en prose, hace un gran elogio del caballero:

Le roman de Lancelot nous fait voir comment (les chevaliers) étaient imbus des maximes du véritable honneur, comment ils observaient religieusement leur parole, comment ils se prenaient à leurs galanteries; jusqu'où ils étaient capables de porter une amitié honnête; quelle reconnaissance ils témoignaient des bienfaits et enfin quels

tro mostrará abiertamente al bienaventurado caballero al que Él eleve a la condición de sirviente suyo entre los demás caballeros terrenales, al que mostrará las grandes maravillas del Santo Graal y le hará ver lo que corazón mortal no podría pensar y lengua de hombre terrenal no podría decir (Alvar, 1982: 46, iii). 
sentiments ils avaient pour le ciel et quel respect pour les choses saintes ${ }^{10}$ (Gegou, 1984: 134).

Así, tras su gran éxito en la literatura francesa de los siglos XII y XIII, la imagen del caballero, y sobre todo la de figuras inolvidables del universo artúrico, como Lanzarote, mucho más que Galaad, continuó alimentando sueños e ideales $\mathrm{y}$, algunas veces, ciertos comportamientos y actitudes.

\section{Obras citadas}

Alvar, Carlos, ed. y trad. 1982. La demanda del Santo Graal. Madrid: Editora Nacional. vol. I.

ed. y trad. 1988. Lanzarote del Lago. Madrid: Alianza. Reimpr.,

BADEL, Pierre-Yves. 1969. Introduction à la vie littéraire du Moyen Age. París: Bordas.

BAUMGARTNER, Emmanuèle. 1995. Le récit médiéval. París: Hachette. . 1994. "Retour des personnages et mise en prose de la fiction arthurienne au XIIIe siècle". De l'Histoire de Troie au Livre du Graal. Le temps, le récit (XIIe-XIIIe siècles). Orléans: Paradigme. 469-484. BouTET, Dominique y Armand STRUBEL. 1979. Littérature et société dans la France dum. París: Presses Universitaires de France.

CHÊNERIE, Marie-Luce. 1986. Le chevalier errant dans les romans arthuriens en vers des XIIe et XIIIe siècles. Ginebra: Droz.

DuBY, Georges. 1988. La société chevaleresque. París: Flammarion. FLORI, Jean. 2001. Caballeros y caballería en la Edad Media. Barcelona: Paidós.

FRAPPIER, Jean. 1972. Etude sur la "Mort le roi Artu", roman du XIIIe siècle. 3a. ed. Ginebra: Droz.

. 1977. "Le Graal et la chevalerie". Autour du Graal. Ginebra:

Droz. 89-128.

${ }^{10}$ La novela de Lanzarote nos muestra cómo (los caballeros) estaban llenos de máximas de verdadero honor, cómo cumplian religiosamente su palabra, cómo se entregaban a sus galanterías; hasta dónde eran capaces de llevar una amistad honesta; qué reconocimiento manifestaban ante las buenas acciones y finalmente qué sentimientos tenían por el cielo y qué respeto por las cosas sagradas. 
García Gual, Carlos. 1994. Historia del rey Arturo y de los nobles y errantes caballeros de la Tabla Redonda. Madrid: Alianza.

GEGOU, Fabienne. 1984. "Lancelot du Lac, le chevalier idéal. Confrontation des points de vue de Jean Chapelain en 1647 et du Graal-Théâtre en 1978". Yvain Lancelot y Gauvain, Colloque arthurien belge de Wégimont. París: Nizet. 133-140.

Hult F., David, ed. y trad. 1994. Chrétien de Troyes, Le Chevalier au Lion. París: Le Livre de Poche.

KÖHLER, Erich. 1974. L'aventure chevaleresque. Ideal et réalité dans le roman courtois. Trad. del alemán por Eliane KAUfHOLZ. París: Gallimard.

LAMART, Jean. 1967. "Les idées morales dans la Mort le roi Artu". Annales de la Faculté Des Lettres en Sciences Humaines de Nice. t. 2. 113131.

LOT, Ferdinand. 1954. Etude sur le "Lancelot en prose". París: Champion. MAURICE, Jean. 1995. La Mort le roi Artu. París: Presses Universitaires de France.

Méla, Charles, ed. 1994. "Le Conte du Graal". Chrétien de Troyes. Romans. París: Le Livre de Poche.

MiCHA, Alexandre. 1980. Essais sur le cycle du "Lancelot en prose". Ginebra: Droz. 1980. Etude sur le "Merlin" de Robert de Boron. Ginebra: Droz. 1976. "La Table Ronde chez Robert de Boron et dans la Queste del saint Graal". De la chanson de geste au roman. Ginebra: Droz.

Mosès, François, ed. y trad. 1991. Lancelot du Lac. París: Le Livre de Poche.

PAUPHILET, Albert, ed. 1984. La Queste del Saint Graal. París: Champion. . 1980. Reimpr. Etudes sur la "Queste del saint Graal". París: Champion.

RoussinEaU, Gilles, ed. 1996. La Suite du Roman de Merlin. Ginebra: Droz.

STANESCO, Michel y Michel ZINK. 1992. Histoire européenne du roman médiéval. París: Presses Universitaires de France. 